\title{
Chemical Constituents and Pharmacological Activities of Steroid Saponins Isolated from Rhizoma Paridis
}

\author{
Fen Liu $\left(\mathbb{D}\right.$, Luning Li $\mathbb{B}^{D}$, Xinchen Tian $\left(\mathbb{D}\right.$, Dengtian Zhang ${ }^{(D)}$, Wenxue Sun $(\mathbb{D}$, \\ and Shulong Jiang $(\mathbb{D}$ \\ Cancer Institue, Jining First People's Hospital, Jining Medical University, Jining 272000, China \\ Correspondence should be addressed to Wenxue Sun; sunwenxue121@126.com and Shulong Jiang; jnsljiang@163.com
}

Received 25 August 2021; Accepted 4 September 2021; Published 17 September 2021

Academic Editor: Weiguo Li

Copyright (c) 2021 Fen Liu et al. This is an open access article distributed under the Creative Commons Attribution License, which permits unrestricted use, distribution, and reproduction in any medium, provided the original work is properly cited.

\begin{abstract}
Rhizoma Paridis, the rhizome of liliaceous plants Paris polyphylla, is one of the most commonly used herbal drugs in China. Phytochemical and pharmacological studies have shown that steroid saponins were the major effective ingredients of Rhizoma Paridis to exert antitumor, anti-inflammatory, hemostasis, and antifibrosis functions. In this review, we discussed the chemical structures of steroid saponins and their related biological activity and mechanisms in cellular and animal models, aiming to provide a reference for future comprehensive exploitation and development of saponins.
\end{abstract}

\section{Introduction}

Rhizoma Paridis, the dried rhizome of liliaceous plants Paris polyphylla Smith var. yunnanensis (Franch.) Hand.-Mazz or Paris polyphylla Smith var. chinensis (Franch.) Hara, is a commonly used herbal drug in China, which has a long clinical application history to treat multiple diseases including malignant boils, carbuncles, snake and insect bites, and injuries [1]. It is also one of the core ingredients of Yunnan Baiyao, a well-known haemostatics Chinese medicine. The Rhizoma Paridis family comprised 24 species discovered in the world, 22 of them was found in the Yunnan, Sichuan, Guizhou, and Guangxi provinces of China [2].

As an essential component of complementary and alternative therapies, medicinal plants have been accepted worldwide to improve health and prevent or cure diseases because of their rich sources and composition diversity. To understand their function and underlying mechanism, it is critical to analyze the major active substances within these plants. Recent phytochemical and pharmacological studies demonstrated that the extract of Rhizoma Paridis contains a large number of chemically active components, including steroid saponins, cholestanol, flavonoids, sterols, and triterpenoids [3-6]. The steroid saponins were shown to be the major effective ingredient exerting antitumor [7], antibacterial [8], antivirus [9], anti-inflammatory [10], hemostasis [11], immune regulation [7], antiliver fibrosis [12], and other biological functions. In particular, the antitumor pharmacological activity of Rhizoma Paridis extracts has emerged a major focus of research. Recent several years, polyphylla saponins have been widely reported to inhibit tumor growth in cancer of the breast [13], liver [14], lung [15], ovary [16], and colon [17], as well as other types of malignancy. All these findings bring lights to the discovery of new drugs for cancer. In this review, we summarized the chemical constituents and pharmacological functions of Rhizoma Paridis extracts and discussed the chemical structures of Paris saponins (PSs), their related biological activity, and potential mechanism.

\section{Chemical Structure of Paris Saponins Derived from Rhizoma Paridis}

Approximately hundreds of steroid saponins, a family of glycosides with a chemical structure that contains either a steroid or a triterpenoid attached via C-3 and an ether bond to a sugar side chain, have been extracted from Rhizoma Paridis, which are considered as the major bioactive ingredients of Paris species [18]. According to the configuration of $\mathrm{C}-25$ and the cyclized state of $\mathrm{F}$ ring in the 
spirostanane structure, steroid saponins are divided into four types (Figure 1): (1) spirostanol, (2) isosprirostanol, (3) furostanol, and (4) pseudospirostanol [3]. Among them, isosprirostanol-type saponins are the main active substance basis of this genus. Moreover, most of the aglycones are diosgenin and pennogenin which generally have hydroxyl substituents at $3 \beta, 7 \beta$, and $17 \beta$ sites and D-glucose, L-rhamnose, and L-arabinose on the sugar groups. The representative active ingredients of isosprirostanol saponins include polyphylin I, polyphylin II, polyphylin V, polyphylin VII, parisyunnanoside G-I, and pariposides A-D. Furthermore, phytochemical investigation shows that pennogenyl saponins mainly exist in Rhizoma Paridis, whereas diosgenyl saponins are rich in Rhizoma Dioscoreae nipponicae [19]. Furostanol-type saponins, with a $\beta$-glucopyranosyl moiety at C-26 of the aglycone, are a class of F-ring cracking compounds. It is generally considered that the furostanol-type saponins are usually the precursor compounds of sprirostanol-type saponins [19]. The aglycones of pseudospirostanol-type saponins are all nautigenin, which can be isolated from the stems and leaves of $P$. diyunnanensis and are also the special components of the upper part of $P$. diyunnanensis. Those nautigenin compounds commonly have hydroxyl substituents at positions 3, 7, 17, and 26. The representative active constituents of pseudospirostanol-type saponins include chonglou SL-9 SL-15 and abutiloside L.

\section{Pharmacological Activities of Paris Saponins}

As described above, PSs extracted from Rhizoma Paridis were capable of exerting antitumor [7], antibacterial [8], antivirus [9], anti-inflammatory [10], hemostasis [11], immune regulation [7], antiliver fibrosis [12], and other biological functions. The possible mechanisms are discussed as follows.

3.1. Antitumor Activity. Accumulating studies have shown various antitumor effects of PS in various tumor models. The underlying mechanisms were associated with inhibiting proliferation, inducing apoptosis, antiangiogenesis, inducing differentiation, blocking metastasis, and reversing multidrug resistance of cancer.

A few studies have investigated the cytotoxicity influence of PS in liver cancer. Pennogenin 3-O-Rha- $(1 \longrightarrow 2)$-[Glc$(1 \longrightarrow 3)$ ]-Glc (Compound 1), polyphyllin D, pb/formosanin C, and polyphyllin VII isolated from Rhizoma Paridis were found to exhibit dose-dependent antitumor effect in HepG2 cells which are involved in a number of signaling pathways including the activation of the Fas and JNK pathways, deregulation of the MAPK pathway, and inhibition of the PI3K/Akt/mTOR pathway. Furthermore, polyphyllin VII was able to cause autophagic cell death and interfere with the metabolism in HepG2 cells [20-22]. Pennogenin 3-O-Rha$(1 \longrightarrow 2)-[$ Glc- $(1 \longrightarrow 3)]-G l c$ (Compound 1$)$ and polyphyllin VII showed significant antitumor activity in HepG2, MCF-7, and PC-3 cells by activation the mitochondrial apoptotic cascades, inhibition of the CDK1 and PI3K/Akt pathways, and modulation of MAPK pathway [23]. Polyphyllin D was revealed to induce the expression of p21 and cyclin E1 leading to G2/M cell cycle arrest in HepG2 cells [21]. A proteomic study demonstrated that PS was capable of downregulation of dUTPase, hnRNP K, and GMP synthase, whereas upregulation of DNase- $\gamma$, nucleoside diphosphate kinase A, and centrin-2 [24]. This study provided a deep insight into the antitumor mechanism of polyphyllin $\mathrm{D}$ and $\mathrm{pb} /$ formosanin C [24]. PS also inhibits the oxidation of fatty acids pathway and the gluconeogenesis cascade, two core metabolic pathways affecting energy metabolism, to block the tumor growth in the H22 mouse hepatocarcinoma model. Interestingly, the effects in the tumor mice appear to be very different from those in normal mice. In a normal animal group, polyphyllin $\mathrm{D}$, pb/formosanin $\mathrm{C}$, polyphyllin V, polyphyllin VI, polyphyllin VII, Paris saponin $\mathrm{H}$, and gracillin significantly reduced the concentration of lipid and glycerate, but increased glucose level. However, these three compounds in H22 mice with hepatocarcinoma had opposite effects, i.e., increase in lipid and glycerate and decrease in glucose level [25]. In addition, the mixed compounds of polyphyllin $\mathrm{D}$ and $\mathrm{pb} /$ formosanin $\mathrm{C}$ exhibited more robust and powerful antitumor effects than either of them alone in HepG2 and Bel-7402 cells. The combinations significantly strengthened cycle arrest at G1 phase and promoted mitochondria-dependent apoptosis in hepatocarcinoma cell [26].

Polyphyllin D, pb/formosanin C, polyphyllin VI, and polyphyllin VII have potent proapoptotic effect on human ovarian cancer. A recent study showed that $\mathrm{pb} /$ formosanin $\mathrm{C}$ induced the expression levels of several proapoptotic proteins, including Bax, cytosolic cytochrome c, activatedcaspase-3, and activated-caspase- 9 in the SKOV3 cellular model [27]. Moreover, formosanin $C$ was shown to suppress NF- $\kappa \mathrm{B}$ signaling, resulting in inhibition of the expression of VEGF and angiogenesis [27]. In addition, reduction of ERK1/2 phosphorylation and Bcl-2 expression was observed upon the treatment of SKOV3 cells with formosanin $\mathrm{C}$ compound [28]. Polyphyllin VII treatment of ovarian cancer cells (A2780 and SKOV3) was found to trigger the mitochondrial location of dynamin-related protein 1 (DRP1) and inhibit the PP2A/AKT pathway, leading to mitochondrial dysfunction [29]. It was also demonstrated that polyphyllin $\mathrm{D}$ promoted apoptosis and hampered migration cells by reducing caspase- 9 and $\mathrm{Wnt} 5 \mathrm{a}$ levels and elevating c-Jun expression in vitro and in vivo [16]. In addition to cytotoxic effects, pb/formosanin C markedly compromised angiogenesis by reduction of VEGF and inhibition of VEGFR2 phosphorylation as well as inactivation of proangiogenic kinases Src, FAK, and Akt in xenograft models established with either SKOV3 or HOC7 cell line [30].

A number of studies have also examined the PS in lung cancer models. In DEN-induced mouse lung cancer, polyphyllin $\mathrm{D}, \mathrm{pb}$ /formosanin $\mathrm{C}$, dioscin, polyphyllin $\mathrm{V}$, polyphyllin VI, polyphyllin VII, Paris saponin $\mathrm{H}$, and gracillin displayed significant inhibitory effects on tumor development and growth, and the possible mechanism was due to reduction of the expression levels of TNF- $\alpha$, IL-6, COX-2, PGE2, CK8, and CK18 and inactivation of the EGFR/PI3K/ Akt, EGFR/Ras/Erk, and NF- $\kappa$ B pathways [15]. In the LA795 


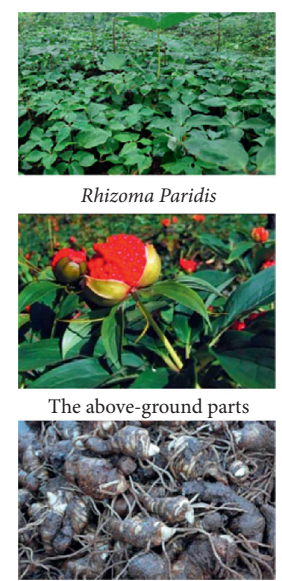

Rhizomes

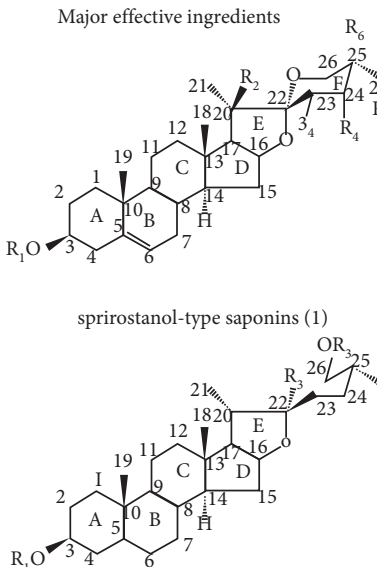

furostanol-type saponins (3)

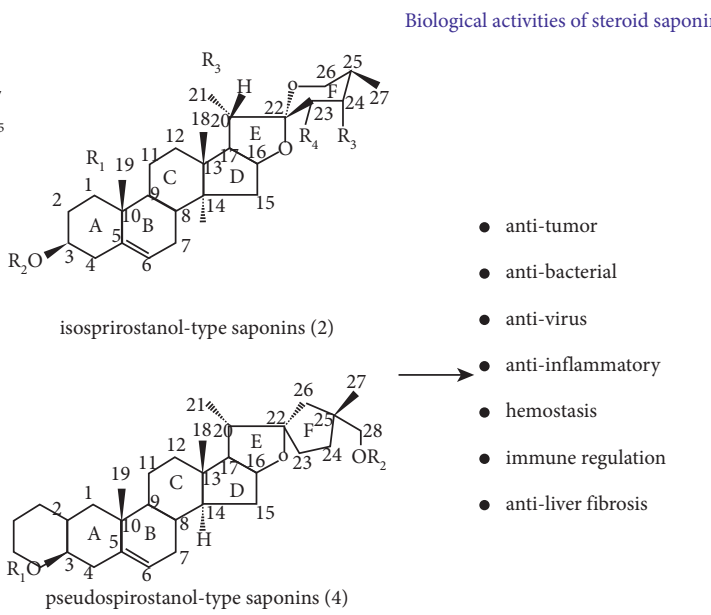

Figure 1: The major effective ingredients of Rhizoma Paridis and their biological activities.

cellular and xenograft model, polyphyllin $\mathrm{D}, \mathrm{pb}$ /formosanin $\mathrm{C}$, dioscin, Paris saponin $\mathrm{H}$, and polyphyllin VII were also shown to have significant antitumor activity by inducing apoptosis and blocking the migration [31]. Moreover, pb/ formosanin $\mathrm{C}$ was found to restrain the proliferation and induce the apoptosis, autophagy, and paraptosis by activation of the JNK pathway in NCI-H460 and NCI-H520 lung cancer cells [32]. In addition, $\mathrm{pb} /$ formosanin $\mathrm{C}$ was able to inhibit cell migration, invasion, and metastases by repression of MMP-2 and MMP-9 enzyme activity as well as MMP-1, -2, -3, -9, and -14 expression in LA795 cells and T739 mice with lung adenocarcinoma [33]. Combination of polyphyllin $\mathrm{D}$ with hyperthermia $\left(43^{\circ} \mathrm{C}\right)$ potently induced apoptosis and $\mathrm{G} 2 / \mathrm{M}$ cell cycle arrest via decrease of $\mathrm{Bcl}-2$ expression and increase of Bax level [34]. Notably, polyphyllin $\mathrm{D}$ was shown to reverse gefitinib-resistance in nonsmall cell lung cancer by increasing $\mathrm{Bax} / \mathrm{Bcl}-2$ ratio and total caspase-3 level both in vitro and in vivo [35].

PSs were also evaluated for their antitumor properties in the cervical cancer model. A previous study showed that polyphyllin VII significantly induced apoptosis in HeLa cells, and the underlying mechanism involved in increasing the expression of caspase- 3 , caspase- 9 , and Bax and decreasing Bcl-2 level [36].

Except for the abovementioned effects, a recent study using UHPLC-qMS spectrum-effect analysis manifested that polyphyllin VII, dioscin, polyphyllin I, and progenin III were identified as the main antitumor chemical compositions in HT29 and MDA-MB-231 cell lines [37]. In addition, polyphyllin VI was shown to trigger $\mathrm{S}$ and G2/M cell cycle arrest and extrinsic apoptosis by activation of the p38/p53 and the caspase $3 / 8$ pathways in tongue squamous carcinoma SCC15 cells [38]. Furthermore, polyphyllin D, Paris saponin H, and polyphyllin VII also displayed notable antitumor and antimetastasis activity in B16 melanoma cells [39].

Interestingly, Paris saponin $\mathrm{H}$ was demonstrated to induce cell cycle arrest at G1 phase and accelerate cell apoptosis by blocking A1 adenosine receptor (ARA1) and ARA3 expression and suppressing the Akt and MAPK cascades in glioma U251 cells [40]. Polyphyllin D also hampered vasculogenic mimicry (VM) formation, an indication of cancer metastasis, through inhibition of the PI3K-Akt-Twist1-VE-cadherin pathway in several HCC cell lines including SMMC7721, PLC, HepG2, Hep3B, and Bel7402 [41].

According to the abovementioned compounds, the antitumor activities of steroid saponins in vitro and in vivo are summarized in Tables 1 and 2 .

Recently, it has been widely used to study the interaction between drugs and proteins by simulating the docking of smallmolecule drug ligands and protein receptor targets [42]. The interaction between ligand and receptor is a process of mutual recognition between molecules through hydrogen bond, electrostatic interaction, and van der Waals force [43]. The binding mode and affinity could be predicted by calculation. In this case, molecular docking is often used as an essential reference for designing targeted drugs and screening effective compounds [44]. Using bioinformatics analysis and molecular docking in hepatitis B virus-related liver cancer, polyphyllin I had been shown to have good affinity with various protein targets, including STAT3, PTP1B, IL2, BCL2L1, FIS1, MFN1, MFN2, and OPA1 $[45,46]$. Computational docking also manifested that polyphyllin I has a high affinity with the allosteric drug and metabolite site of AMPK, which induces autophagy and inhibits NSCLC cell growth after activation. This finding was further supported by microscale thermophoresis (MST) and drug affinity responsive targeting stability (DARTS) assays [47].

3.2. Anti-Inflammatory. Polyphyllin $\mathrm{D}$ has been show to inhibit LPS/IFN- $\gamma$-stimulated inflammatory cytokine secretion from peritoneal elucidated macrophages (PEMs) and attenuate IKK $\alpha / \beta$ and p 65 phosphorylation in vitro. Furthermore, polyphyllin I alleviated the bone erosion and synovitis and prevented M1-like macrophage and T-cell infiltration from ankle joint in the collagen-induced arthritis (CIA) mouse model [48]. Polyphyllin D has also been demonstrated to suppress the inflammation by inhibition of the activation of NF- $\kappa$ B pathway in acne. Accordingly, inflammatory cytokines, including interleukin (IL)-6, IL-8, and 
Table 1: Efficacy of Rhizoma Paridis-derived steroid saponins against cancer in vitro.

\begin{tabular}{|c|c|c|c|}
\hline Compound & Cell line and IC50 & Targeting pathways & Ref. \\
\hline \multirow{5}{*}{ Polyphyllin D } & HepG2 (4.01 uM, 24h) & Fas and JNK pathways; p53-Bax/Bcl-2 and p53-p21-cyclin E/ & {$[21]$} \\
\hline & Bel-7402 (4.74 uM, 24h) & CDK2 pathways; NF-kB and MMP-9 & {$[25,26]$} \\
\hline & PC-9 $(2.69 \mu \mathrm{g} / \mathrm{ml}, 48 \mathrm{~h})$ & $\mathrm{Bcl}-2 / \mathrm{Bax}$ & {$[34]$} \\
\hline & $\begin{array}{c}\text { PC-9-ZD }(2.51 \mu \mathrm{g} / \mathrm{ml}, 24 \mathrm{~h} ; 2.07 \mu \mathrm{g} / \mathrm{ml}, 48 \mathrm{~h} ; \\
1.53 \mu \mathrm{g} / \mathrm{ml}, 72 \mathrm{~h})\end{array}$ & $\mathrm{Bax} / \mathrm{Bcl}-2$-caspase-3 & {$[35]$} \\
\hline & Hela $(2.62 \mu \mathrm{M}, 24 \mathrm{~h})$ & Bcl-2/Bax-caspase-3/9 & [36] \\
\hline \multirow{6}{*}{$\begin{array}{l}\mathrm{Pb} / \text { formosanin } \\
\mathrm{C}\end{array}$} & HepG2 (13.62 ug/mL, $24 \mathrm{~h} ; 3.29 \mathrm{ug} / \mathrm{mL}, 48 \mathrm{~h})$ & \multirow{2}{*}{$\begin{array}{c}\text { NMR metabolic pathways } \\
\text { p53-Bax/Bcl-2 and p53-p21-cyclin E/CDK2 pathways; NF-kB } \\
\text { and MMP-9 }\end{array}$} & [22] \\
\hline & Bel-7402 (4.36 uM, 24 h) & & {$[25,26]$} \\
\hline & $\begin{array}{c}\text { SKOV3 }(20.99 \mathrm{uM}, 24 \mathrm{~h} ; 10.44 \mathrm{uM}, 48 \mathrm{~h} ; \\
8.83 \mathrm{uM}, 72 \mathrm{~h})\end{array}$ & $\mathrm{NF}-\kappa \mathrm{B}-\mathrm{VEGF}$ and NF- $\kappa \mathrm{B}-\mathrm{Bcl}-2 / \mathrm{Bcl}-\mathrm{xL}$ & {$[27]$} \\
\hline & $\begin{array}{c}\text { CaSki }(5.7 \mu \mathrm{M}), \text { SiHa }(3.7 \mu \mathrm{M}), \text { HEC-1A } \\
(2.1 \mu \mathrm{M}) \text {, and A549 }(4.0 \mu \mathrm{M})\end{array}$ & Bax-caspase-3/9 and ERK/Bcl-2 & {$[28]$} \\
\hline & HOC-7 $(6.44 \mathrm{uM}, 48 \mathrm{~h})$ & VEGF & [30] \\
\hline & $\begin{array}{c}\text { NCI-H460 }(2.0 \mu \mathrm{M}, 48 \mathrm{~h}) \text { and NCI-H520 } \\
(1.6 \mu \mathrm{M}, 48 \mathrm{~h})\end{array}$ & JNK pathway & {$[32]$} \\
\hline Compound 1 & $\begin{array}{l}\text { HepG2 }(2.35 \mathrm{uM}, 48 \mathrm{~h}) \\
\text { MCF-7 }(2.59 \mathrm{uM}, 48 \mathrm{~h}) \\
\text { PC-3 }(4.76 \mathrm{uM}, 48 \mathrm{~h})\end{array}$ & $\begin{array}{l}\text { Mitochondrial apoptotic, CDK1, PI3K/Akt, and MAPK } \\
\text { pathways }\end{array}$ & [23] \\
\hline \multirow[t]{2}{*}{$\begin{array}{l}\text { Polyphyllin } \\
\text { VII }\end{array}$} & $\begin{array}{l}\text { HepG2 }(1.77 \mathrm{uM}, 48 \mathrm{~h}) \\
\text { MCF-7 }(2.71 \mathrm{uM}, 48 \mathrm{~h}) \\
\text { PC-3 }(4.67 \mathrm{uM}, 48 \mathrm{~h})\end{array}$ & $\begin{array}{l}\text { Mitochondrial apoptotic, CDK1, PI3K/Akt, and MAPK } \\
\text { pathways }\end{array}$ & {$[23]$} \\
\hline & $\begin{array}{c}\mathrm{A} 2780(3.0 \mu \mathrm{M}, 24 \mathrm{~h}) \text { and SKOV3 }(3.0 \mu \mathrm{M}, \\
24 \mathrm{~h})\end{array}$ & PP2A/AKT/DRP1 signaling axis & [29] \\
\hline Polyphyllin VI & $\begin{array}{c}\text { SCC-15 }(25.80 \mu \mathrm{M}, 24 \mathrm{~h} ; 21.22 \mu \mathrm{M}, 48 \mathrm{~h} ; \\
19.57 \mu \mathrm{M}, 72 \mathrm{~h})\end{array}$ & p38/p53 and caspase $3 / 8$ pathways & {$[38]$} \\
\hline $\begin{array}{l}\text { Paris saponin } \\
\mathrm{H}\end{array}$ & $\mathrm{U} 251(100 \mu \mathrm{g} / \mathrm{ml}, 48 \mathrm{~h})$ & ARA1/ARA3 and Akt/MAPK & {$[40]$} \\
\hline
\end{tabular}

TABLE 2: Summary of the anticancer activities of steroid saponins in vivo.

\begin{tabular}{|c|c|c|c|}
\hline Animal models & Drug dose & Effects & Ref. \\
\hline $\begin{array}{l}\text { HepG2 xenografts in } \\
\text { nude mice }\end{array}$ & $\begin{array}{l}\text { Intraperitoneal injection with } 1 \text { or } 3 \mathrm{mg} / \mathrm{kg} \\
\text { compound } 1 \text { and polyphyllin VII for } 3 \\
\text { weeks }\end{array}$ & $\begin{array}{l}\text { Compound } 1 \text { and polyphyllin VII significantly and dose- } \\
\text { dependently inhibited the growth of HepG2 xenografts } \\
\text { through regulation of MAPK and PI3K/Akt pathways }\end{array}$ & [20] \\
\hline $\begin{array}{l}\text { SKOV3 xenografts in } \\
\text { nude mice }\end{array}$ & $\begin{array}{l}\text { Intraperitoneal injection with } 1,2 \text {, and } \\
3 \mathrm{mg} / \mathrm{kg} \text { polyphyllin VII for } 3 \text { weeks }\end{array}$ & $\begin{array}{l}\text { Polyphyllin VII markedly restrained tumor growth } \\
\text { meanwhile increased the ratio of BAX/BCL- } 2 \text { and cleaved } \\
\text { caspase- } 3 \text { expression }\end{array}$ & [29] \\
\hline $\begin{array}{l}\text { SKOV3 or HOC- } 7 \\
\text { xenografts in nude } \\
\text { mice }\end{array}$ & $\begin{array}{l}\text { Intraperitoneal injection with } 1,2 \text {, and } \\
3 \mathrm{mg} / \mathrm{kg} \mathrm{pb} / \text { formosanin } \mathrm{C} \text { for } 4 \text { weeks }\end{array}$ & $\begin{array}{c}\text { Formosanin C remarkably compromised angiogenesis by } \\
\text { reduction of VEGF and inhibition of VEGFR2 } \\
\text { phosphorylation as well as inactivation of proangiogenic } \\
\text { kinases Src, FAK, and Akt }\end{array}$ & {$[30]$} \\
\hline $\begin{array}{l}\text { PC-9-ZD xenografts in } \\
\text { nude mice }\end{array}$ & $\begin{array}{c}2,4 \text {, and } 8 \mathrm{mg} / \mathrm{kg} \text { polyphyllin } \mathrm{D} \text { by gavage } \\
\text { administration for } 2 \text { weeks }\end{array}$ & $\begin{array}{l}\text { Polyphyllin D treatment robustly decreased 18F-FDG-uptake } \\
\text { compared with the control group }\end{array}$ & [35] \\
\hline $\begin{array}{l}\text { PLC xenografts in nude } \\
\text { mice }\end{array}$ & $\begin{array}{l}\text { Intragastrical administration with } 10 \mathrm{mg} / \mathrm{kg} \\
\text { polyphyllin D for } 25 \text { days }\end{array}$ & $\begin{array}{l}\text { Polyphyllin D hampered vasculogenic mimicry (VM) } \\
\text { formation, an indication of cancer metastasis, through } \\
\text { inhibition of the PI3K-Akt-Twist1-VE-cadherin pathway }\end{array}$ & [41] \\
\hline
\end{tabular}

tumor necrosis factor (TNF)- $\alpha$ were decreased after Paris I treatment [49]. In addition, polyphyllin $G$ was shown to be able to decrease the synthesis of $\mathrm{NO}$ and $\mathrm{PGE}_{2}$ and reduce the expressions of cytokines (TNF- $\alpha$, IL- $1 \beta$, and IL-6) and enzymes (inducible NO synthase, cyclooxygenase-2, and matrix metalloproteinase-9) at both protein and mRNA levels [10].

3.3. Antifibrosis. Liver fibrosis is a pathological change in the structure and function of the liver, resulting from excessive proliferation and abnormal deposition of extracellular matrix (ECM) components. Progression of liver fibrosis may lead to cirrhosis or hepatocellular carcinoma [50]. However, liver fibrosis is reversible and PS had been reported as one of the effective therapeutic agents. It has been demonstrated that polyphyllin G, polyphyllin VI, pb/formosanin $\mathrm{C}$, and polyphyllin $\mathrm{D}$ were efficacious in improving $\mathrm{CCl}_{4}$-induced hepatic fibrosis and cirrhosis in Sprague Dawley rat models. These 4 compounds not only relieved the degeneration and 
necrosis of liver tissue but also reduced the degree of fibroplastic proliferation via the suppression of VEGF, ERK1/2, RASAL1, PDGF, and $\alpha$-SMA $[12,51,52]$. Furthermore, polyphyllin $G$ was also shown to induce the apoptosis of hypertrophic scar fibroblasts through the modulation of the ERK/JNK pathway [53]. Collectively, these results indicate that PS is a class of potential antifibrosis agents, which deserve future serious investigation.

3.4. Hemostasis. As described above, Rhizoma Paridis is a key ingredient of two Chinese hemostasis medicines, "Yunnan Baiyao" and "Gongxuening" [1]. Thus, it has been widely used as a hemostatic medicine in China. A recent study demonstrated that Paris saponin $\mathrm{H}$ significantly enhanced thrombin activity, thereby shortening the bleeding time in the mouse tail snipping model, suggesting that Paris saponins could interact with thrombin [54]. Polyphyllin VII was found to act directly on platelets and hemostasis and cause $62 \%$ platelet aggregation at $300 \mathrm{ug} / \mathrm{ml}$ concentration [11]. Another study showed that polyphyllin VII, polyphyllin II, dioscin, and polyphyllin I all could serve as favorable hemostatic agents [37]. These results indicate that PSs are promising candidates for development of hemostatic drugs.

3.5. Other Effects. Polyphyllin $G$ has been shown to be a potential stimulator of interferon gene (STING) agonist, which initiates macrophages activation and accelerates cytotoxic $\mathrm{T}$ lymphocytes infiltration in tumor microenvironment. In the meantime, polyphyllin $G$ treatment robustly increased the expression of PD-L1 on macrophages, suggesting that the combination polyphyllin $\mathrm{G}$ with anti-PD1/ PD-L1 immunotherapy is beneficial for the cancer treatment [55]. In addition, predominant antibacterial activity against propionibacterium acnes was found in several PSs including chonglouoside SL-2, chonglouoside SL-3, chonglouoside SL6 , trillin, polyphyllin $\mathrm{V}$, diosgenin $3-\mathrm{O}-\mathrm{Rha}-(1 \longrightarrow 4)$-Glc, dioscin, pennogenin 3 -O-Rha-( $\longrightarrow 4)$-Rha- $(1 \longrightarrow 4)$-Glc, polyphyllin VII, and methylprotodioscin [8].

\section{Conclusions and Prospect}

Active ingredients extracted from medicinal plants and metabolic products are the primary resources for developing medical drugs. The compounds isolated from Rhizoma Paridis have significant pharmacological activities, among which steroid saponins are the major active material components. Saponins have antitumor, antifibrosis, anti-inflammatory, hemostasis, and other properties. In particular, polyphyllin $\mathrm{D}$, pb/formosanin $\mathrm{C}$, polyphyllin VI, and polyphyllin VII displayed considerable antitumor activity in both in vitro and in vivo cancer models. The possible mechanisms include inducing cell apoptosis, hampering angiogenesis, inhibiting cell invasion and metastasis, regulating the tumor microenvironment, and reversing tumor drug resistance. Several signaling pathways were modulated by these compounds, including PI3K/Akt, Ras/Erk, mTOR, $\mathrm{PP} 2 \mathrm{~A}$, and NF- $\kappa \mathrm{B}$ cascades. Hepatic fibrosis and cirrhosis have been one of the most serious diseases to cure.
Polyphyllin D, pb/formosanin C, polyphyllin VI, and polyphyllin VII exhibited dramatic antifibrosis activities against liver fibrosis and cirrhosis.

In summary, the saponins have great potential for anticancer and antifibrosis drug discovery. The chemical constituents and biological activities of isolated sterol saponins need to be further studied.

\section{Abbreviations}

\section{PSs: $\quad$ Paris saponins}

Fas: $\quad$ Factor-related apoptosis

JNK: $\quad$-Jun N-terminal kinase

MAPK: $\quad$ Mitogen-activated protein kinase

PI3K: $\quad$ Phosphoinositide 3-kinase

mTOR: Mammalian target of rapamycin

CDK1: Cyclin-dependent kinase 1

Bax: Bcl-2-associated X

Bcl-2: B-cell leukemia/lymphoma 2

VEGF: Vascular endothelial growth factor

NF- $\kappa$ B: $\quad$ Nuclear factor kappa-B

Caspase-3: Cysteine-aspartic acid specific protease 3

Caspase-9: Cysteine-aspartic acid specific protease 9

ERK1/2: Extracellular-regulated kinase 1/2

DRP1: Dynamin-related protein 1

PP2A: $\quad$ Protein phosphatase 2A

VEGFR2: Vascular endothelial growth factor receptor 2

Src: $\quad$ Sarcoma gene

FAK: $\quad$ Focal adhesion kinase

TNF- $\alpha$ : Tumor necrosis factor alpha

IL-6: $\quad$ Interleukin-6

COX-2: Cyclooxygenase-2

PGE2: $\quad$ Prostaglandin E2

CK8: $\quad$ Cytokeratin 8

CK18: $\quad$ Cytokeratin 18

MMP-2: Matrix metallopeptidase 2

MMP-9: Matrix metallopeptidase 9

ARA1: $\quad$ A1 adenosine receptor

ARA3: $\quad$ A3 adenosine receptor

VM: Vasculogenic mimicry

LPS: Lipopolysaccharides

IFN- $\gamma$ : Interferon $\gamma$

PEMs: $\quad$ Peritoneal elucidated macrophages

IKK $\alpha / \beta$ : $\quad$ Inhibitor of nuclear factor kappa-B kinase $\alpha / \beta$

CIA: $\quad$ Collagen-induced arthritis

NO: $\quad$ Nitric oxide

PGE2: Prostaglandin E2

ECM: $\quad$ Extracellular matrix

RASAL1: Ras GTPase-activating-like protein 1

PDGF: Platelet-derived growth factor

$\alpha$-SMA: $\quad \alpha$-Smooth muscle actin

STING: $\quad$ Stimulator of interferon gene

PD-L1: $\quad$ Programmed death ligand 1

PD-1: $\quad$ Programmed cell death protein-1.

\section{Data Availability}

All data included in this study are available upon request by contact with the corresponding author. 


\section{Conflicts of Interest}

The authors declare that they have no conflicts of interest.

\section{Authors' Contributions}

Shulong Jiang and Wenxue Sun contributed to the conception of the review. Fen Liu wrote the manuscript with support from Shulong Jiang, Luning Li, and Wenxue Sun. Xinchen Tian and Dengtian Zhang collected the related literature. All authors have read and approved the final version of the manuscript.

\section{Acknowledgments}

This work was supported in part by the National Natural Science Foundation of China (grant no. 81873249) and the Young Taishan Scholars Program of Shandong Province (grant no. tsqn201909200).

\section{References}

[1] C. P. Commission, Pharmacopoeia of the People's republic of China, China Medical Science Press, Beijing, China, 2015.

[2] X. Wu, L. Wang, G.-C. Wang et al., "New steroidal saponins and sterol glycosides from Paris polyphylla var. yunnanensis," Planta Medica, vol. 78, no. 15, pp. 1667-1675, 2012.

[3] J.-C. Wei, W.-Y. Gao, X.-D. Yan, Y. Wang, S.-S. Jing, and P.-G. Xiao, "Chemical constituents of plants from the GenusParis," Chemistry and Biodiversity, vol. 11, no. 9, pp. 1277-1297, 2014.

[4] Y. Ling, Z. Fu, Q. Zhang, L. Xu, and L. Liao, "Identification and structural elucidation of steroidal saponins from the root ofParis polyphylla by HPLC-ESI-QTOF-MS/MS," Natural Product Research, vol. 29, no. 19, pp. 1798-1803, 2015.

[5] X. Wu, L. Wang, H. Wang, Y. Dai, W.-C. Ye, and Y.-L. Li, "Steroidal saponins from Paris polyphylla var. yunnanensis," Phytochemistry, vol. 81, pp. 133-143, 2012.

[6] Y. Zhao, L. P. Kang, Y. X. Liu et al., "Steroidal saponins from the rhizome of Paris polyphylla and their cytotoxic activities," Planta Medica, vol. 75, no. 4, pp. 356-363, 2009.

[7] Y. Tian, G. Y. Gong, L. L. Ma, Z. Q. Wang, D. Song, and M. Y. Fang, "Anti-cancer effects of Polyphyllin I: an update in 5 years," Chemico-Biological Interactions, vol. 316, Article ID 108936, 2020.

[8] X.-J. Qin, D.-J. Sun, W. Ni et al., "Steroidal saponins with antimicrobial activity from stems and leaves of Paris polyphylla var. yunnanensis," Steroids, vol. 77, no. 12, pp. 1242-1248, 2012.

[9] B. Joshi, S. K. Panda, R. S. Jouneghani et al., "Antibacterial, antifungal, antiviral, and anthelmintic activities of medicinal plants of Nepal selected based on ethnobotanical evidence," Evidence-based Complementary and Alternative Medicine: eCAM, vol. 2020, p. 1043471, Article ID 1043471, 2020.

[10] C. Zhang, C. Li, X. Jia et al., "Vitro and in vivo anti-inflammatory effects of polyphyllin VII through downregulating MAPK and NF-kappaB pathways," Molecules, vol. 24, no. 5, 2019.

[11] C.-L. Sun, W. Ni, H. Yan et al., "Steroidal saponins with induced platelet aggregation activity from the aerial parts of Paris verticillata," Steroids, vol. 92, pp. 90-95, 2014.

[12] S. Man, W. Fan, W. Gao et al., "Anti-fibrosis and anti-cirrhosis effects of Rhizoma paridis saponins on diethylnitrosamine induced rats," Journal of Ethnopharmacology, vol. 151, no. 1, pp. 407-412, 2014.

[13] Z.-Z. Xie, M.-M. Li, P.-F. Deng et al., "Paris saponin-induced autophagy promotes breast cancer cell apoptosis via the Akt/ mTOR signaling pathway," Chemico-Biological Interactions, vol. 264, pp. 1-9, 2017.

[14] J. Liu, S. Man, J. Li, Y. Zhang, X. Meng, and W. Gao, "Inhibition of diethylnitrosamine-induced liver cancer in rats by Rhizoma paridis saponin," Environmental Toxicology and Pharmacology, vol. 46, pp. 103-109, 2016.

[15] S. Man, J. Li, P. Qiu et al., "Inhibition of lung cancer in diethylnitrosamine-induced mice byRhizomaparidis saponins," Molecular Carcinogenesis, vol. 56, no. 5, pp. 1405-1413, 2017.

[16] L. Gu, J. Feng, Z. Zheng, H. Xu, and W. Yu, "Polyphyllin I inhibits the growth of ovarian cancer cells in nude mice," Oncology letters, vol. 12, no. 6, pp. 4969-4974, 2016.

[17] W.-J. Teng, P. Chen, F.-Y. Zhu et al., "Effect of Rhizoma paridis total saponins on apoptosis of colorectal cancer cells and imbalance of the JAK/STAT3 molecular pathway induced by IL-6 suppression," Genetics and Molecular Research, vol. 14, no. 2, pp. 5793-5803, 2015.

[18] T. Zhang, H. Liu, X.-T. Liu, D.-r. Xu, X.-q. Chen, and Q. Wang, "Qualitative and quantitative analysis of steroidal saponins in crude extracts from Paris polyphylla var. yunnanensis and P. polyphylla var. chinensis by high performance liquid chromatography coupled with mass spectrometry," Journal of Pharmaceutical and Biomedical Analysis, vol. 51, no. 1, pp. 114-124, 2010.

[19] X. Huang, W. Gao, S. Man, G. Ying, and C. Liu, "Isolation and identification of compounds present in rhizomes of paris axialis H. Li and study of their cytotoxic effects," Latin American Journal of Pharmacy, vol. 30, no. 3, pp. 540-545, 2011.

[20] Y.-S. Chen, Y. He, C. Chen et al., "Growth inhibition by pennogenyl saponins from Rhizoma paridis on hepatoma xenografts in nude mice," Steroids, vol. 83, pp. 39-44, 2014.

[21] Y. Zeng, Z. Zhang, W. Wang et al., "Underlying mechanisms of apoptosis in HepG2 cells induced by polyphyllin I through Fas death and mitochondrial pathways," Toxicology Mechanisms and Methods, vol. 30, no. 6, pp. 397-406, 2020.

[22] Y. Li, S. Man, J. Li et al., "The antitumor effect of formosanin C on HepG2 cell as revealed by $1 \mathrm{H}-\mathrm{NMR}$ based metabolic profiling," Chemico-Biological Interactions, vol. 220, pp. 193-199, 2014.

[23] F.-Y. Long, Y.-S. Chen, L. Zhang et al., "Pennogenyl saponins induce cell cycle arrest and apoptosis in human hepatocellular carcinoma HepG2 cells," Journal of Ethnopharmacology, vol. 162, pp. 112-120, 2015.

[24] Z.-X. Cheng, B.-R. Liu, X.-P. Qian et al., "Proteomic analysis of anti-tumor effects by Rhizoma Paridis total saponin treatment in HepG2 cells," Journal of Ethnopharmacology, vol. 120, no. 2, pp. 129-137, 2008.

[25] S. Man, W. Fan, Z. Liu et al., "Antitumor pathway of Rhizoma Paridis Saponins based on the metabolic regulatory network alterations in H22 hepatocarcinoma mice," Steroids, vol. 84, pp. 17-21, 2014.

[26] J. Liu, S. Man, Z. Liu, L. Ma, and W. Gao, "A synergistic antitumor effect of polyphyllin I and formosanin C on hepatocarcinoma cells," Bioorganic \& Medicinal Chemistry Letters, vol. 26, no. 20, pp. 4970-4975, 2016.

[27] M. Yang, J. Zou, H. Zhu et al., "Paris saponin II inhibits human ovarian cancer cell-induced angiogenesis by 
modulating NF- $\kappa$ B signaling," Oncology Reports, vol. 33, no. 5, pp. 2190-2198, 2015.

[28] X. Xiao, J. Zou, T. M. Bui-Nguyen et al., "Paris Saponin II of Rhizoma Paridis - a novel inducer of apoptosis in human ovarian cancer cells," BioScience Trends, vol. 6, no. 4, pp. 201-211, 2012.

[29] L. Zhao, Z. Liu, X. Deng et al., "Polyphyllin VII induces mitochondrial apoptosis by regulating the PP2A/AKT/DRP1 signaling axis in human ovarian cancer," Oncology Reports, vol. 45, 2020.

[30] X. Xiao, M. Yang, J. Xiao et al., "Paris Saponin II suppresses the growth of human ovarian cancer xenografts via modulating VEGF-mediated angiogenesis and tumor cell migration," Cancer Chemotherapy and Pharmacology, vol. 73, no. 4, pp. 807-818, 2014.

[31] M. Shuli, G. Wenyuan, Z. Yanjun, M. Chaoyi, Y. Liu, and L. Yiwen, "Paridis saponins inhibiting carcinoma growth and metastasis in vitro and in vivo," Archives of Pharmacal Research, vol. 34, no. 1, pp. 43-50, 2011.

[32] S. Man, P. Lv, J. Cui et al., "Paris saponin II-induced paraptosis-associated cell death increased the sensitivity of cisplatin," Toxicology and Applied Pharmacology, vol. 406, Article ID 115206, 2020.

[33] S. Man, W. Gao, Y. Zhang et al., "Formosanin C-inhibited pulmonary metastasis through repression of matrix metalloproteinases on mouse lung adenocarcinoma," Cancer Biology \& Therapy, vol. 11, no. 6, pp. 592-598, 2011.

[34] P. Zhao, H. Jiang, D. Su, J. Feng, S. Ma, and X. Zhu, "Inhibition of cell proliferation by mild hyperthermia at $43^{\circ} \mathrm{C}$ with Paris Saponin I in the lung adenocarcinoma cell line PC-9," Molecular Medicine Reports, vol. 11, no. 1, pp. 327-332, 2015.

[35] H. Jiang, P.-J. Zhao, D. Su, J. Feng, and S.-L. Ma, "Paris saponin I induces apoptosis via increasing the Bax/Bcl-2 ratio and caspase- 3 expression in gefitinib-resistant non-small cell lung cancer in vitro and in vivo," Molecular Medicine Reports, vol. 9, no. 6, pp. 2265-2272, 2014

[36] W. Zhang, D. Zhang, X. Ma, Z. Liu, F. Li, and D. Wu, "Paris saponin VII suppressed the growth of human cervical cancer Hela cells," European Journal of Medical Research, vol. 19, no. 1, p. 41, 2014.

[37] X. Qiao, C. Qu, Q. Luo et al., "UHPLC-qMS spectrum-effect relationships for Rhizoma Paridis extracts," Journal of Pharmaceutical and Biomedical Analysis, vol. 194, Article ID 113770, 2021.

[38] J.-Y. Ke, W. Zhang, R.-S. Gong et al., “A monomer purified from Paris polyphylla (PP-22) triggers $S$ and G2/M phase arrest and apoptosis in human tongue squamous cell carcinoma SCC- 15 by activating the p38/cdc25/cdc2 and caspase 8/caspase 3 pathways," Tumor Biology, vol. 37, no. 11, pp. 14863-14872, 2016.

[39] S. Man, W. Gao, Y. Yan, Z. Liu, and C. Liu, "Inhibition of matrix metalloproteinases related to metastasis by diosgenyl and pennogenyl saponins," Journal of Ethnopharmacology, vol. 137, no. 3, pp. 1221-1227, 2011.

[40] L. Bi, Y. Liu, Q. Yang et al., "Paris saponin H inhibits the proliferation of glioma cells through the A1 and A3 adenosine receptormediated pathway," International Journal of Molecular Medicine, vol. 47, no. 4, 2021.

[41] T. Xiao, W. Zhong, J. Zhao et al., "Polyphyllin I suppresses the formation of vasculogenic mimicry via Twist1/VE-cadherin pathway," Cell Death \& Disease, vol. 9, no. 9, p. 906, 2018.

[42] A. Khursheed, V. Jain, A. Rasool, M. A. Rather, N. A. Malik, and A. H. Shalla, "Molecular scaffolds from mother nature as possible lead compounds in drug design and discovery against coronaviruses: a landscape analysis of published literature and molecular docking studies," Microbial Pathogenesis, vol. 157, Article ID 104933, 2021.

[43] P. E. Hansen, "NMR of natural products as potential drugs," Molecules, vol. 26, no. 12, 2021.

[44] M. M. Salman, Z. Al-Obaidi, P. Kitchen, A. Loreto, R. M. Bill, and R. Wade-Martins, "Advances in applying computer-aided drug design for neurodegenerative diseases," International Journal of Molecular Sciences, vol. 22, no. 9, 2021.

[45] S. Yu, W. Gao, P. Zeng et al., "Exploring the effect of Polyphyllin I on hepatitis B virus-related liver cancer through network pharmacology and in vitro experiments," Combinatorial Chemistry and High Throughput Screening, vol. 24, 2021.

[46] S. Yu, W. Gao, P. Zeng et al., "Exploring the effect of Gupi Xiaoji Prescription on hepatitis B virus-related liver cancer through network pharmacology and in vitro experiments," Biomedicine and Pharmacotherapy, vol. 139, Article ID 111612, 2021

[47] Y. Wu, Y. Si, Y. Xiang et al., "Polyphyllin I activates AMPK to suppress the growth of non-small-cell lung cancer via induction of autophagy," Archives of Biochemistry and Biophysics, vol. 687, Article ID 108285, 2020.

[48] Q. Wang, X. Zhou, Y. Zhao et al., "Polyphyllin I ameliorates collagen-induced arthritis by suppressing the inflammation response in macrophages through the NF- $\kappa \mathrm{B}$ pathway," Frontiers in Immunology, vol. 9, Article ID 2091, 2018.

[49] T. Zhu, W. Wu, S. Yang, D. Li, D. Sun, and L. He, "Polyphyllin I inhibits propionibacterium acnes-induced inflammation in vitro," Inflammation, vol. 42, no. 1, pp. 35-44, 2019.

[50] E. L. Ellis and D. A. Mann, "Clinical evidence for the regression of liver fibrosis," Journal of Hepatology, vol. 56, no. 5, pp. 1171-1180, 2012.

[51] Y. Han, L. Pan, S. Ran et al., "Rhizoma Paridis saponins ameliorates hepatic fi brosis in rats by downregulating expression of angiogenesisassociated growth factors," Molecular Medicine Reports, vol. 19, no. 5, pp. 3548-3554, 2019.

[52] Y. Hong, Y.-Q. Han, Y.-Z. Wang et al., "Paridis Rhizoma Sapoinins attenuates liver fibrosis in rats by regulating the expression of RASAL1/ERK1/2 signal pathway," Journal of Ethnopharmacology, vol. 192, pp. 114-122, 2016.

[53] C. Zhong, Q. Nong, W. Feng et al., "Polyphyllin VII induces fibroblasts apoptosis via the ERK/JNK pathway," Burns, vol. 47, no. 1, pp. 140-149, 2021.

[54] F. Wen, T. Chen, H. Yin, J. Lin, and H. Zhang, "Vitro effects on thrombin of paris saponins and in vivo hemostatic activity evaluation of paris fargesii var. brevipetala," Molecules, vol. 24, no. 7, 2019.

[55] J. Yu, H. Deng, and Z. Xu, "Targeting macrophage priming by polyphyllin VII triggers anti-tumor immunity via STINGgoverned cytotoxic T-cell infiltration in lung cancer," Scientific Reports, vol. 10, no. 1, Article ID 21360, 2020. 